\title{
Peer assisted learning model to support students' success in a complex science course
}

\author{
Kathryn Osborne ${ }^{1}$, Maha Othman*2 \\ ${ }^{1}$ School of Baccalaureate Nursing, St. Lawrence College, Kingston, Ontario, Canada \\ ${ }^{2}$ Department of Biomedical and Molecular Sciences, Queens's University, Kingston, Ontario, Canada
}

Received: April 30, 2019

DOI: $10.5430 /$ jnep.v9n11p53
Accepted: August 5, 2019

Online Published: August 26, 2019

\begin{abstract}
The application of peer learning models, including Peer Assisted Learning (PAL), has been primarily in the clinical and simulation settings with the focus on readiness for clinical and professional practice. We present a single center experience with the design, structure and implementation of an in-house PAL tutorial in a Pathophysiology; a complex mandatory 12 weeks science course taken by 2 nd-year students. This experience represents a phase and progression towards a more coherent model. In phase I, a short survey was conducted to gauge the students' interest and assess the feasibility of a tutorial model. In Phase II and III, PAL tutorials were introduced and implemented over the course of two semesters for two cohorts of students. Phase I provided sufficient evidence to proceed with tutorial development, and provided guidance for tutorial planning and implementation. Phase II and III showed tutorial participation gradually increased over time. We have integrated complexity science as a theoretical basis that guided the study and unified the findings throughout the study. The tutorials helped students to integrate concepts from related courses, encouraged them to find similarities, and enhanced overall understanding of course content, while providing a support system to reduce anxiety and stress. The use of online material and a concept mapping approach received the most significant positive feedback as learning tools. We believe the PAL approach is important to tutorial development and, when implemented within the theoretical model of complexity science, may carry potential in developing nursing or other curricula. Further research into the application of tutorial models more broadly in nursing education curriculum is necessary to determine more coherently the unique design characteristics required.
\end{abstract}

Key Words: Small group learning, Tutorial, Pathophysiology teaching, Peer assisted learning

\section{INTRODUCTION}

\subsection{Rationale and objective}

Education within various disciplines of health care, including nursing, is at the forefront of change and innovation; becoming increasingly complex and diverse. This has led educators and curriculum developers to move away from passive learning structures (i.e. lecture), and consider new forms of integrated and active learning; this includes group work, online activities, and in-class participation using mobile technology (e.g. clickers, cellphones) ${ }^{[1,2]}$ While these approaches seek to bring greater depth and learning to the classroom, outside support structures for students remain limited and unchanged from self-directed, independent study, or one-to-one tutoring.

Today's health care undergraduate students, like most other academic domains are experiencing increased levels of stress,

\footnotetext{
* Correspondence: Maha Othman; Email: mothman@sl.on.ca; Address: School of Baccalaureate Nursing, St. Lawrence College, 100 Portsmouth Avenue, Kingston, Ontario, Canada.
} 
anxiety and depression. ${ }^{[3-6]}$ In Baccalaureate nursing programs, stress as a result of overwhelming course material, has been cited as a primary reason for withdrawal. ${ }^{[7]}$ Higher levels of stress and associated hormones, impair cortical processing required for learning and retention, leading to poorer academic performance outcomes, as well as negative mental and physical health effects. ${ }^{[8]}$

It is for these reasons, that this study focuses on how peer assisted learning (PAL) has the potential to promote integrated understanding of course content, develop critical thinking skills, and create opportunities for leadership and the establishing peer support networks.

To date, there is limited literature on the application of PAL in nursing education outside the clinical practice and simulation contexts. The majority of research looks to the mentorship opportunities and development of practice skills, leaving a gap in the potential for PAL to be applied in core curricula contexts. This report seeks to address this gap. We hereby share our experience in the design, structure and implementation of PAL tutorials in a 2nd-year undergraduate nursing pathophysiology course. This is an in-house PAL model which we developed according to students' needs. We hopewith this small pilot study- to stimulate further discussion and enhance the applications of PAL in various disciplines of undergraduate education. We utilize complexity theory as means of creating a unifying approach to the project and thereby addressing the nature of health care and the nursing profession as interrelated, adaptive systems, and thus requiring educational approaches that reflect such dynamic characteristics.

\subsection{Context for change}

Pathophysiology is a mandatory 12-week course taken by 2nd-year nursing students in $\mathrm{BScN}$ program, (St. Lawrence College, Kingston, ON). Students in the program are typically between the ages of 18 and 35, many having previous University degrees or College diplomas, additional family responsibilities, or are retraining for a second career. The course focuses on disease processes, manifestations, and associated treatment approaches, necessary to make and understand clinical decisions in nursing practice. This makes it central to other nursing courses and also future nursing practice. Given the demanding nature of the course both in content and workload, as well as the interrelated nature of content with other courses and clinical practice, it is an optimal selection for the implementation of course-based tutorials. ${ }^{[9]}$

Prior to the start of this study, peer academic support for students was limited to $1: 1$ tutoring for those at risk of fail- ure, or otherwise struggling academically within the course. This could lead to larger group tutorials when the number of requests for tutoring reached a specific threshold. While this model is useful to ensure limited resources are distributed most economically, it limits opportunities for students more broadly and may cause students to have to wait until they are already struggling before receiving needed academic support.

The tutorial model presented in this study features optional student-led tutorials offered alongside the course, to all students, and under the guidance of the course Professor.

\subsection{Peer assisted learning in higher education}

Tutorials, often taught by teaching assistants (TAs) in related science-based courses, as well as other small group learning methodologies have existed for centuries and are becoming more prevalent in North American and other Western higher education institutions. ${ }^{[10]}$ The tutorial model provides opportunities for more diverse learning approaches and experiences, allowing for bidirectional learning from both the tutor/facilitator and group/participants. ${ }^{[11,12]}$

The utilization of peer learning models in higher education can be applied in many forms and the terminology varies to include "peer assisted learning", "near-peer teaching", and "peer-led team learning", among others. For this study, we apply the concept of peer assisted learning (PAL) as a method of teaching that is provided by an upper-year student to lower-year students in an informal, small group setting. [11] PAL uses a constructivist approach that views learning as a social process to create meaning from abstract concepts. ${ }^{[13]}$

PAL programs are prevalent in the United Kingdom, Australia, as well as some European and Eastern Asian countries, providing an extensive source of literature to access in the development of a PAL model. Benefits of PAL for students stem from the ability to create an open, informal environment for discussion, and include: greater depth of understanding of course content; developing transferable skills in areas like time management and study techniques; as well as providing mutual support and reassurance through shared experiences. ${ }^{[12,14,15]}$ Students also improve their independent study skills and gain a sense of autonomy in taking responsibility for their learning. ${ }^{[16]}$ In addition, the peer tutor, or facilitator, also benefits from the opportunity to act as a mentor for other students, thereby gaining confidence and leadership skills. ${ }^{[12,14]}$

The application of peer learning models, including PAL, in nursing education has been primarily in the clinical and simulation settings with the focus on readiness for clinical and professional practice. ${ }^{[14,15]}$ PAL was selected for this study as it provides unique flexibility in delivery models while 
maintaining a constructivist and social pedagogical approach to learning.

\subsection{Complexity as a unifying approach to peer assisted learning}

Complexity has grown in nursing education curriculum development and research with the recognition of health, health care, and nursing as interrelated, adaptive systems. ${ }^{[2]}$ The use of complexity takes form in complexity theory, thinking, teaching, and pedagogy. The concept of complex adaptive systems as inherently unpredictable, composed of interacting elements, dynamic in nature, exhibit emergency in their ability to learn and adapt to new and changing conditions. ${ }^{[17]}$

Applying complexity to nursing education provides a framework for creating approaches that promote learning as emergent and dynamic rather than solely content-driven and inherently static. ${ }^{[18]}$ One way to develop these thinking patterns is a learner-centered approach ${ }^{[19]}$ which can be based on PAL experiences and open discussion formats. ${ }^{[16,23]}$

\section{MethodS}

\subsection{Tutorial development and implementation}

This project was undertaken over a period of three years each representing a phase and progression towards a more coherent model in Figure 1. The first phase was a survey to gauge students' interest and the feasibility of a tutorial model. The goal was to ensure students' perspectives were taken into consideration and integrated into tutorial planning and implementation. The second and third phases represent the two-year development and implementation of tutorials within the course over two semesters for two cohorts of students. The following section highlights the processes, methods applied in each phase as well as the successes and challenges.

Study Overview: 3 Years, 3 Phases

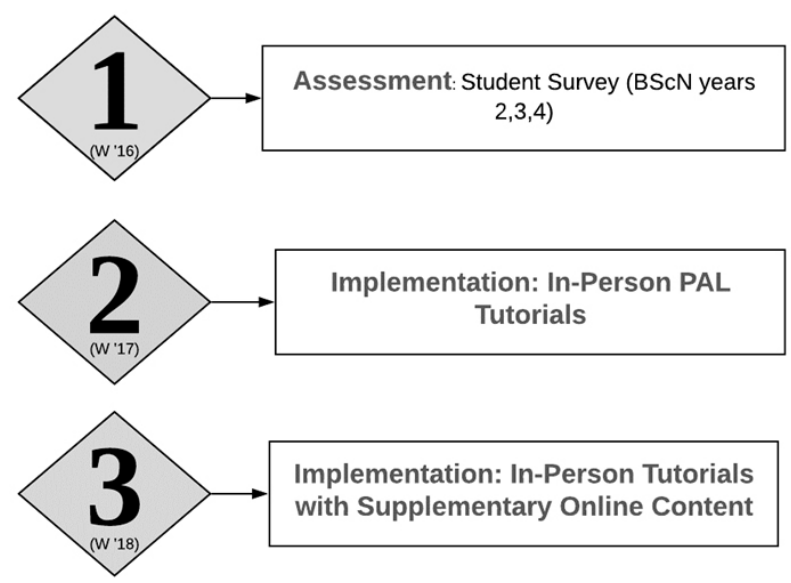

Figure 1. Three phases of study

\subsection{Phase I: Needs assessment}

In the first year, a short survey created by the authors was administered to 2 nd \& 3 rd year students. The primary aims were to examine students' receptiveness for adding course tutorials the course and determine potential barriers to their attendance if any. Our secondary aim was to identify the types of challenges experienced by students who completed this course previously to assist in guiding tutorial planning and development. After obtaining research ethics board approval, the survey was administered through a link on Blackboard; the college's online learning platform.

\subsection{Phase II: Tutorial 1}

Preliminary results from Phase 1 provided sufficient evidence to proceed with tutorial development and implementation. Results also provided guidance indicating time management and scheduling as the most significant potential challenges to uptake. Two in-person tutorials were made available each week, one during the lunch break and one on the weekend, beginning in the 4th week of the course. This scheduling provided greater flexibility for students and allowed us to compare how each scheduling option impacted attendance. The 4th week was selected because this is when systemic pathophysiology content begins.

Tutorials were scheduled outside of class time, voluntary, and attendance or participation was not connected to course evaluations. This meant that attendance relied on student interest and commitment requiring the facilitator and faculty support to develop meaningful content and delivery methods that would be beneficial to students and encourage attendance. The peer tutor/ facilitator was an upper year student who successfully completed the course, and received initial training from the course Professor along with guidance and support for the first year of the tutorial (phase II). Their role was reinforcement of key points from the lecture, integration of concepts, engaging peers in innovative ways for learning and addressing more broadly challenges they face with the course including workload, stress, or content delivery methods.

\subsection{Phase III: Tutorial 2}

Taking personal observations and student comments from Phase 2 of the project, we began Phase 3 in the first week of the course. Initially, we were to include at least one lunch period tutorial as the year before, but scheduling conflicts meant that only weekends and some weekdays were available. However, to strive for greater flexibility and access to content, we created online resources available to students through the Blackboard Learning Platform. As in Phase 2, a minimum of two 1-hour tutorial sessions was made available 
per week, with additional sessions added in the afternoon or evening around midterm and final exams as time permitted. This allowed for further comparison between scheduling of tutorials and participation rates across the two student cohort populations.

\section{RESULTS}

\subsection{Student demographics}

While demographic data was not collected in this study, utilizing data obtained from annual reports published by Colleges Ontario and St. Lawrence College provide a demographic profile of nursing students enrolled in the $\mathrm{BScN}$ program and participating throughout the three phases of the study. Enrollment at the St. Lawrence College-Kingston campus represents $1.9 \%$ of the total number of college collaborative nursing students across Ontario (a total of 13, 494 students). ${ }^{[19,20]}$ Just $28.5 \%$ of students enter College from high-school leaving the majority of students as "indirect" applicants indicating a more mature and varied demographic make-up with many having families, started a career, or completed previous post-secondary education. ${ }^{[20,21]}$

Demographic characteristics of applicants to the College of Nurses of Ontario, the Provincial licensing body for Registered Nurses, the majority of Ontario graduates are female, and between the ages of 18 and 35. ${ }^{[21]}$ These Provincial statistics are representative of the sampling frame and smaller sample group participants in this study.

\subsection{Phase I}

The survey response rate was $31 \%$ with results evenly distributed between the 2 nd and 3rd year students, providing a 2-year representation of student perceptions (see Table 1). As shown in Figure 2, overall, 92\% of respondents perceived tutorials will be helpful to their learning and/or success in the course. $32.4 \%$ responded they would make an effort to attend the tutorials, while the remaining $59.6 \%$ responded that the tutorials would need to either be made a part of the course schedule, or that they would be too busy to attend. These results indicate scheduling conflicts and challenges in time management as significant barriers to attendance, especially given many would not attend the tutorials despite perceiving them as helpful to their learning and course success.

When questioned on tutorials themselves, there were consistent results between 56 and $70 \%$ agreement on all positive aspects posed. In contrast, few students agreed with the negative statements towards tutorials, with the exception that the course load is already too high to support the addition of a tutorial. This result correlates well to the question of where the greatest source of challenge exists within the course, where $97.3 \%$ of students indicated the overwhelming content of the course.

\subsection{Phase II}

Despite initially low turnouts for the start of Phase II of the tutorials, participation gradually increased to an average of 3-4 with increased attendance during lunch periods and around exam times. These were ideal sizes for the groups and promoted high levels of discussion lead by the facilitator. Groups under 3 or over 7 became more difficult to manage or did not stimulate the discussion that would be desired for beneficial learning, and often defaulted to a lecture format. Furthermore, students emphasized a preference for visual representations of concepts as they felt this helped to piece together readings and create a more integrated whole.

When questioned on the scheduling of tutorials, students found that lunch breaks were preferable to weekends because they were already on campus and it did not conflict with other commitments such as work, clinical practice, and family. Students also provided feedback that tutorials should start earlier, rather than in the 4th week when systemic pathophysiology began, because it is often the foundations that are most difficult to learn and yet are applied as the course progresses.

\subsection{Phase III}

In Phase III, students again expressed a significant challenge in filtering information and identifying areas of strength and weakness. Planning was often very short-term and focused on upcoming exams and assignments in each course, increasing the level of stress and anxiety at impending deadlines. A common phenomenon was that students would memorize concepts for a specific exam and then immediately forget these as they attempted to learn the content for the next exam, even if both had similar content. This meant students continued to miss course connections and studied content multiple times in different contexts, creating unneeded time constraint. For the students whom attended tutorials more often, a focus on integrating concepts from related courses was encouraged. Initially students were surprised that they could find similarities and simultaneously study from multiple courses while gaining a greater understanding of the content as a whole. However, as they continued to discuss and build on their knowledge connections there was notable relief and relaxation in their demeanor and attitude within the tutorials.

Despite positive developments over the semester in Phase 2 , Phase 3 exhibited a notable decrease in attendance and participation, averaging 1-2 students and a peak of 3-4 prior to exams. However, the use of online material was viewed as helpful and several students utilized these resources. A 
key focus in Phase 3, also taken from participant feedback in Phase 2, was to create more visual and interactive content with the goal of facilitating connections. This resulted in an early form of concept mapping. As shown in Figures 3 and 4, whereby course content was represented in a web that connected processes with symptomatology, treatment, and associated diseases or disorders. This approach received the most significant positive feedback from participants as a learning tool that enhanced their overall understanding of course content.

Tables 2 and 3 show Facilitator's time commitment and preparation involved.

Table 1. Phase I: Peer-assisted learning preliminary survey results (2016)

\begin{tabular}{lc}
\hline Questionnaire Items & Percen \\
\hline 1. Year of Study & \\
2nd-Year & $48.7 \%$ \\
3rd-Year & $51.4 \%$ \\
2. Area(s) of most difficulty in pathophysiology & \\
a. Understanding concepts in general & $29.8 \%$ \\
b. Linking materials with previous and current courses & $13.5 \%$ \\
c. Applying learning to real-life situations & $16.2 \%$ \\
d. The overwhelming amount of information & $97.3 \%$ \\
3. Helpfulness of tutorials and expected participation & \\
a. "I would find this helpful and make time to attend" & $32.4 \%$ \\
b. "I would find this helpful but it would have to be made part of my course schedule" & $37.8 \%$ \\
c. "I would find this helpful but would be too busy to attend" & $21.6 \%$ \\
d. "I would not find this helpful but believe others would benefit" & $2.7 \%$ \\
e. "I would not find this helpful at all" & $5.4 \%$
\end{tabular}

\section{Preferred timing of tutorials}
a. "On lunch break"
$48.7 \%$
b. "Early breakfast meeting"
$16.2 \%$
c. "Evening during the week"
$32.4 \%$
d. "Weekends"
$8.1 \%$
e. "My schedule doesn't allow anymore time for tutorials"
$21.6 \%$
f. "I would not come/It would not help me"
$8.1 \%$

\section{Perceived positives/values of tutorials}

a. "Open up an interactive, dynamic and safe space for discussion” $\quad 62.2 \%$

b. "Allow students to contribute to their own learning" $\quad 59.5 \%$

$\begin{array}{ll}\text { c. "Provide an avenue for immediate and detailed formative feedback" } & 70.7 \%\end{array}$

d. "Provide a chance for better student-teacher relationship that reinforces learning" $\quad 65.6 \%$

e. "Provide flexibility for creative ways of learning and applying information" $\quad 56.8 \%$

f. "Encourage peer support"

\section{Perceived negatives/challenges of tutorials*}
a. "Tutorials are too much work"
$11.1 \%$
b. "The course load is already very high to add a tutorial"
$69.4 \%$
c. "Working in groups of any form creates anxiety"
$19.4 \%$
d. "Tutorials only benefit auditory and visual learners"
$8.3 \%$
e. "Not all group members are engaged"
$38.9 \%$
f. "There are no negatives to small group tutorials"
$25.0 \%$

*Note. 36/37 participants responded to this question. 
Helpfulness

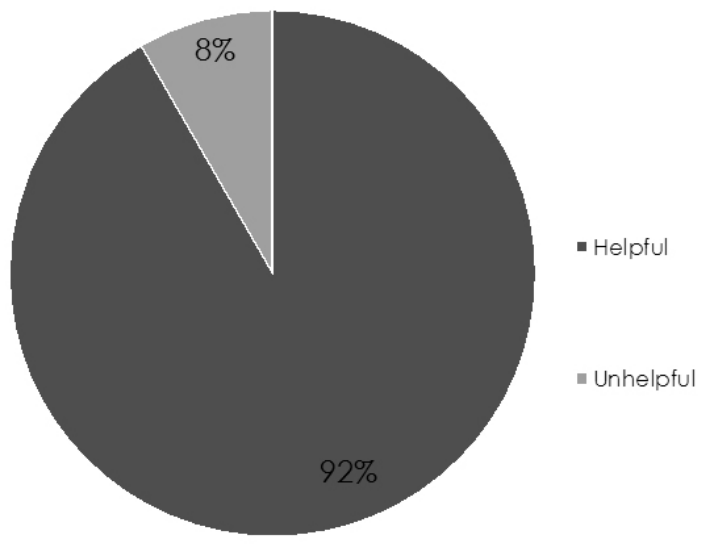

Further Breakdown

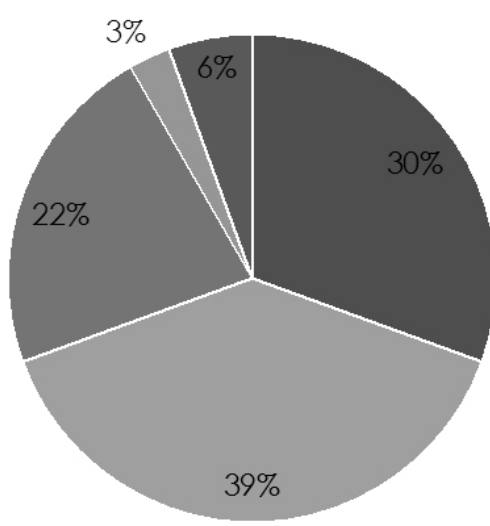

Figure 2. Student Perceptions of Tutorial Helpfulness and Predicted Attendance

Table 2. Phase II Tutorial-Facilitator's time commitment and preparation involved (W-2017)

\begin{tabular}{ll}
\hline Tutorial Preparation Phase II & Hours/Week \\
\hline Prep by Facilitator per week & 3 \\
Additional prep for final exam review and presentation & 4 \\
Class visit and initial meeting & 0.3 \\
Total Hours for project duration & 34.3 \\
Average Facilitator commitment & 10 \\
\hline
\end{tabular}

\section{Discussion}

Frequent dialogue and process evaluation with students was an essential component throughout tutorial development as a means of tailoring tutorials to student needs. Initially, the emphasis was put on content review and application to personal experience and clinical practice with the goal of producing critical thinking. While this accomplished goals related to course content, students continued to struggle with the amount of information in conjunction with content from other courses. Over time, students increasingly identified learning the more fundamental tasks of time management and prioritization of information to be more challenging than the content itself, prompting a change in the tutorial content to practice filtering information, developing effective study schedules, managing stress, and identifying strengths and weaknesses.

Table 3. Phase III Tutorial- Facilitator's time commitment and preparation involved (W-2018)

\begin{tabular}{ll}
\hline Tutorial Preparation Phase III & Hours/Week \\
\hline Prep by Facilitator per week to include both in-person and online content & 5 \\
Additional preparation for final exam review and presentation (previous presentation used for foundation) & 3 \\
$\begin{array}{l}\text { Total hours for project duration } \\
\text { Average facilitator commitment } \\
\text { (prep+delivery; excluding additional prep for final exam) }\end{array}$ & 63 \\
\hline
\end{tabular}

One common observation throughout both years of tutorial implementation, was the tendency of students to lack insight into their strengths, weaknesses, and learning preferences. Many students expressed feeling overwhelmed at the volume of material they were expected to know, without recognizing what they did know and building on this knowledge. In addition, students focused on memorizing information required for tests rather than approaching course material with the goal to understand fundamental concepts, incorporate new and exceptional information, and then apply this knowledge more broadly to questions. While memorization is a useful approach to basic information such as definitions, this narrow focus may mean lead to students missing potential links between and across subject areas. In contrast, tutorials provided an open and discussion-focused environment not only for review of material, but for the application of that knowledge across courses. 


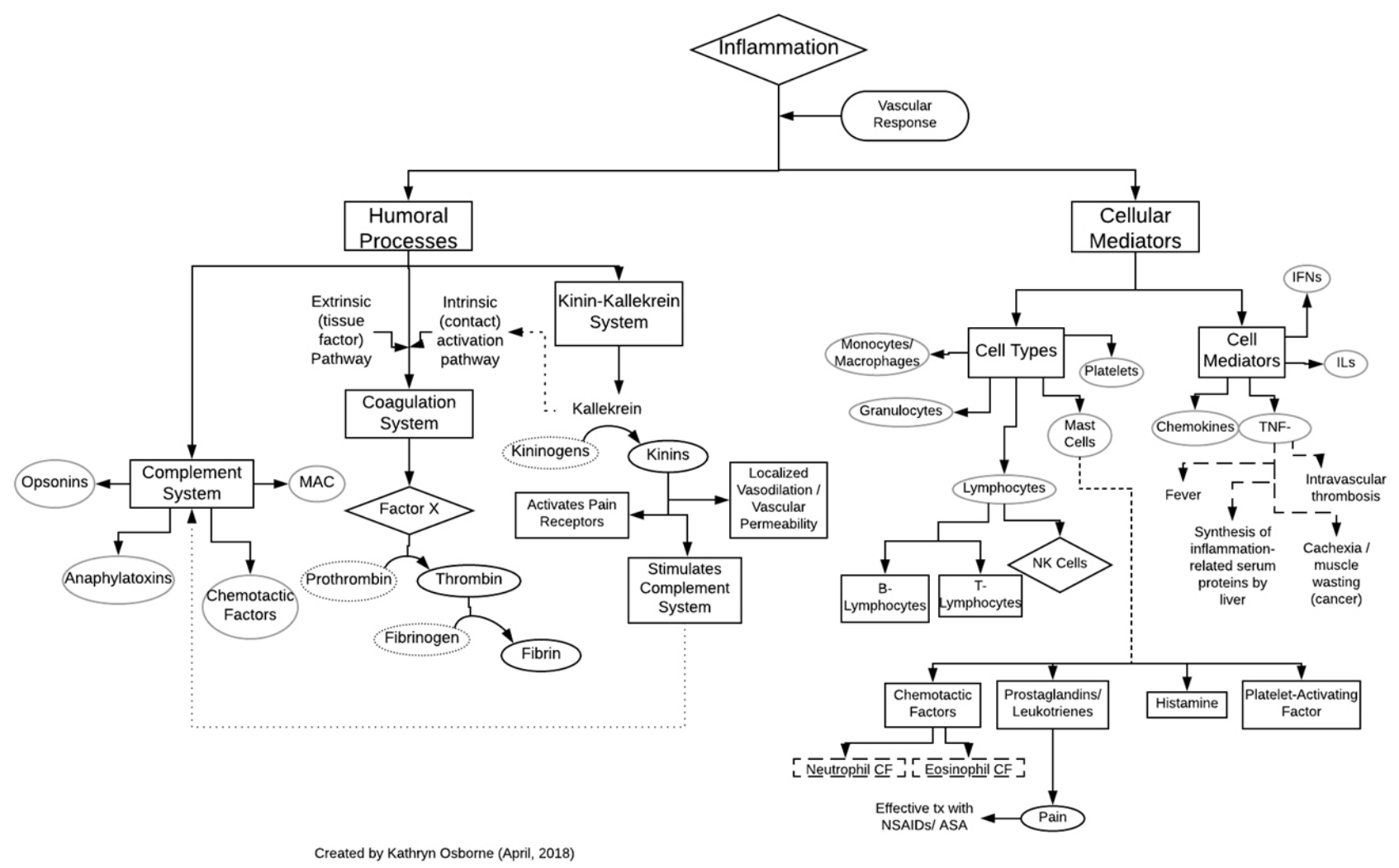

Figure 3. Concept Map-Integrated Processes of Inflammation

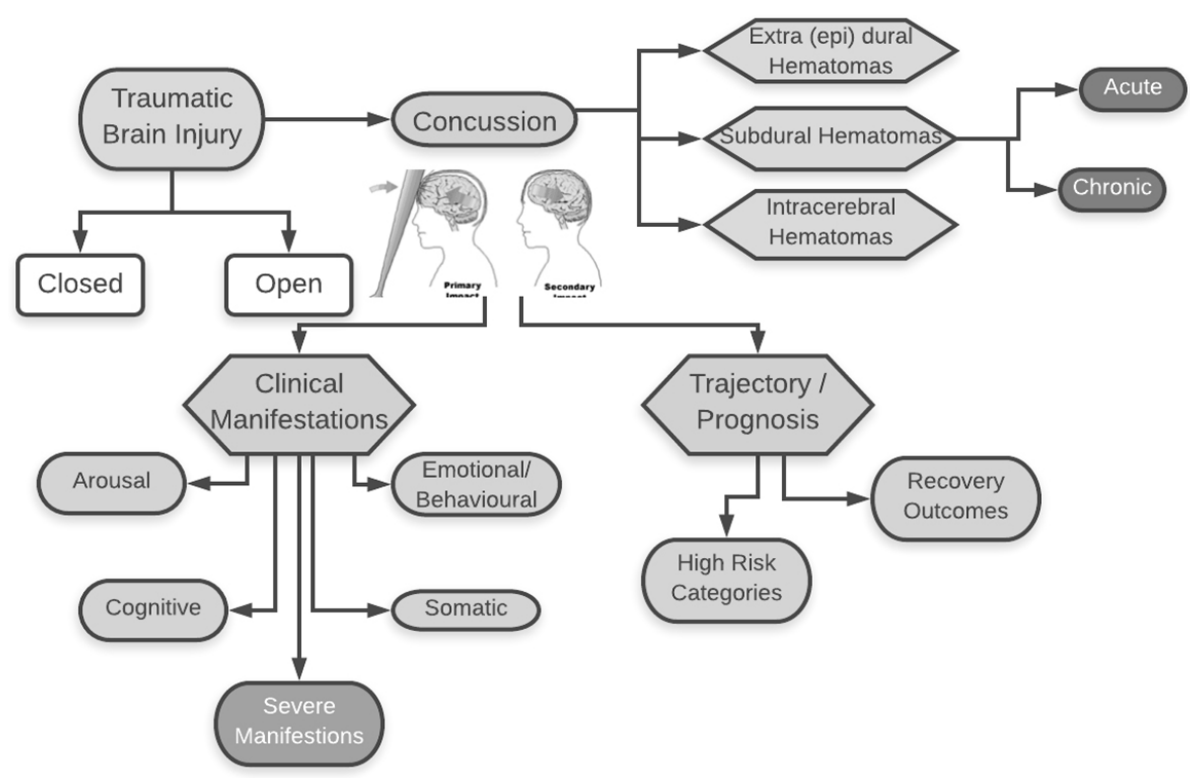

Figure 4. Concept Map-Traumatic Brain Injury

It is this level of integrative learning and holistic system approaches that is the focus of complexity science approaches to education and allows for scaffolding of knowledge and the incorporation of context-relevant, real-life components into student learning. ${ }^{[2]}$ This study demonstrates how PAL can de- liver this form of learning as the relationships between peers create the environment necessary to make the connections essential in this form of learning. As students made these connections, they would present a sense of relief, recognizing that they could continue to apply knowledge from one course 
to another, simultaneously increasing their understanding and comfort with the content. This also led to more efficient and effective studying by breaking a common thinking pattern that each subject is fundamentally different from each other and therefore even information that is shared across disciplines, such as human anatomy and physiology, is perceived as new information within each subject being taught. For example, the distribution and function of potassium within the body and the alteration of that critical electrolyte to maintain homeostasis and in the various pathological conditions, are not different, whether you are learning it in a clinical chemistry, nursing practice, or pathophysiology class, rather, the context changes to provide a whole picture of how potassium functions and contributes to overall body function and disease development. However, students would re-read the function of potassium in each subject treating it each time as new information, and subsequently unable to build on the information presented in each class and create a more holistic understanding of body functioning. This contributed to the feelings of being overwhelmed and stressed, and information was harder to recall, ${ }^{[5,8]}$ thereby reinforcing the initial belief that they need to better memorize and review. Breaking this circular thinking pattern by clarifying and practicing a scaffolding approach of integrating new information was facilitated by the tutorial student lead; a peer who has had the learning experience and can integrate concepts across courses. This example also shows pathophysiology itself as a having inherent complexity as a subject, and thereby being a suitable focus for a tutorial integrating course concepts moving away from a 'silo' approach of content-driven courses to create complex system structures of knowledge. ${ }^{[2,17,18]}$

The introduction of concept mapping in Phase 3 had the greatest observed success as a learning tool within the tutorials. The concept map is becoming widely used in nursing education and it has been found to facilitate the transition from rote memorization to meaningful active learning and to promote the development of critical thinking skills required for 21 st-century health care. ${ }^{[23]}$ Visualizing material through the concept map was helpful to both the facilitator and learner to stimulate discussion and organize information as a starting point for making connections to other courses and clinical or personal experience. ${ }^{[23]}$ When concept mapping was used as an interventional strategy in a medical-surgical nursing course, it was found that, when controlling for other factors, the experimental group showed higher gains critical thinking scores in pre-test and post-test results. ${ }^{[24]}$ Observations of our early application of concept mapping in PAL further extends the potential for its use in nursing education. Computerassisted concept mapping has been introduced as a more flexible means for producing concept maps and presents an opportunity for even greater diversity in delivering this tool to students using an online format. ${ }^{[25]}$

Many students found that having the information presented in a relaxed setting with a facilitator who enjoyed the subject and was able to relate directly to their own experiences in the course made the information itself seem more approachable. In addition, as a student themselves, the facilitator is wellpositioned to provide mutual support for students as they move through the course. However, it is important to note that the expectation of the facilitator is not to act as counsellor or take on responsibility for overall student success. Rather they provide a mutual support system and recommend additional professional services as necessary should the student require them. The importance of having facilitators with the knowledge, commitment, and leadership characteristics is essential to the success and sustainability of the program. While this study focuses on the experiences of a single peer facilitator, the insights on tutorial design and delivery presented in this report can be used as a starting point for further research to create peer facilitator training and development programs.

Low participation was the greatest challenge we faced in the tutorials. Fluctuations in attendance, with a noticeable decrease occurring in Phase 3, can be attributed to lack of promotion and unfamiliarity with the tutorial approach and associated value ${ }^{[11,12]}$ as well as expected variations in individual learning preferences that accompany each new cohort of students. McMaster University Medical School is at the forefront of peer assisted learning approaches in Canada with the implementation of Problem-Based Learning (PBL) groups. They found that familiarity with the lecture format combined with an aversion to group work, created resistance from students. ${ }^{[26]}$ While this may result in challenges in the attendance and participation rates, our observations have shown that when students are exposed to the format, these initial preconceptions can be broken-down and they become more active participants. Having multiple approaches and activities available allows for greater flexibility to tailor tutorials for each unique cohort of students and facilitators, including a blend of online, interactive, and in-person methods.

Another potential barrier for creating a sustainable tutorial model, is the recruitment and quality of facilitators. Despite beneficial outcomes in confidence and leadership, Peer Facilitators may also experience frustration, apprehension, and dissatisfaction when unrealistic expectations to teach are placed on them by students. ${ }^{[12,27]}$ From the perspective of the facilitator, effective implementation of tutorials depends on having concrete objectives, a strong understanding of the 
material to be presented, as well as openness and flexibility to explore new topics as they arise through discussion.

Providing facilitator training and clear tutorial objectives not only helps to mitigate these potential negative outcomes, but are also key to the quality and success of a PAL program. ${ }^{[11]}$ Facilitators and students must also be patient and recognize that not all tutorials will have the same success, and this is not a failure, but a learning opportunity to develop and improve one's own skills as well as the tutorial model itself. What is clear from previous research and observations in this report is that a standardized approach to facilitator training and delivery is essential for student participants to derive benefits and continued participation. Furthermore, having a designated person for students and facilitators to access should challenges arise will be important to ensure that quality standards are maintained.

Strong faculty support and supervision is essential for the success of PAL, especially in the early phases of tutorial implementation. ${ }^{[1,26]}$ It is important that there is frequent communication in the development of tutorial content and objectives to ensure that learning is relevant and accurate for students. In addition, those leading or facilitating the tutorials should receive initial training and ongoing support for skill development and to manage unforeseen challenges in managing and delivering tutorials. While McMaster's classic PBL format was not used in this project, one similar challenge faced in our tutorials is that students who are more familiar with the lecture format and how to achieve positive results within it, and therefore may not see the benefit of attending a tutorial. ${ }^{[26]}$

Finally, it is important to consider the characteristics in both physical and virtual environments and how this impacts learning for students. In Patterson et al., ${ }^{[28]}$ looking at how students select and create personal learning environments, when students were presented with a wide variety of modalities, how each student responds is still dependent on their learning preferences. Creating options available in multiple formats may be one way of reaching more students, but educators must be willing to adapt to the approaches based on changing preferences among cohorts, and peer facilitators can act as an important communication line creating the space for those conversations and advocating for tools and resources to meet the needs of their peers. For example, utilizing online platforms to make content discussed in tutorials available online immediately following tutorial delivery and thus providing better access to tutorial content for those unable to attend in person.

\section{Conclusions}

In this study, we share our experience from developing an in-house PAL model that supports students in a complex science course. We have detailed the process of development and implementation based on students' needs. We believe there is a potential for this specifically developed model to positively influence outcomes across similar and related complex courses. The model has also the potential to be applied in other courses and disciplines beyond nursing.

Further research into the application of tutorial models more broadly in modifying curricula is necessary to determine more coherently the unique design characteristics required. In addition, interventional studies evaluating academic outcomes as well as changes in course satisfaction, level of understanding, and confidence are necessary to compare and evaluate the impact of PAL over time. Our experience in introducing a tutorial provides a starting point for future projects and outlines positives and challenges.

\section{Limitations}

This study is small, based on single center and is exchanging experience in one course. The low student participation at times due to time management and scheduling conflicts, have prevented the objective evaluation of the impact of PAL on course outcomes and the generation of statistically useful information.

\section{ACKNOWLEDGEMENTS}

The authors would like to acknowledge St Lawrence College's Applied Research for funding the study.

\section{CONFlicts of InTEREST Disclosure}

The authors declare that there is no conflict of interest.

\section{REFERENCES}

[1] Canadian Nurses Association. Practice of Registered Nurses [Internet]. 2015. 36 p. Available from: https://www.cna-aiic.ca/ / media/cna/page-content/pdf-en/framework-for-the-p racice-of-registered-nurses-in-canada.pdf?la=en

[2] Rosenau P, Watson L, Vye-Rogers L, et al. Educating for Complexity
In Nursing Practice: A Baccalaureate Curriculum Innovation. Qual Adv Nurs Educ en Form Infirm [Internet]. 2015 [cited 2018 Sep 21]; 1(3). https://doi.org/10.17483/2368-6669.1039

[3] Bartlett ML, Taylor H, Nelson JD. Comparison of Mental Health Characteristics and Stress Between Baccalaureate Nursing Students and Non-Nursing Students. J Nurs Educ. 2016 Feb 1 [cited 2018 Sep 
21]; 55(2): 87-90. PMid:26814818 https://doi.org/10.3928/ 01484834-20160114-05

[4] Horgan A, Sweeney J, Behan L, et al. Depressive symptoms, college adjustment and peer support among undergraduate nursing and midwifery students. J Adv Nurs. 2016 Dec 1; 72(12): 3081-92. PMid:27434204 https ://doi.org/10.1111/jan.13074

[5] Holmes A, Silvestri R. Rates of Mental Illness and Associated Academic Impacts in Ontario's College Students. Can J Sch Psychol. 2016 Mar 4; 31(1): 27-46. https://doi.org/10.1177/082957 3515601396

[6] Glauser W. Postsecondary campuses responding to record anxiety and depression levels. Can Med Assoc J. 2017; 189(48): E1501-2. PMid:29203623 https ://doi .org/10.1503/cmaj .109-5512

[7] Health Canada. Nursing Issues: Education. 2006.

[8] Vogel S, Schwabe L. Learning and memory under stress: implications for the classroom. npj Sci Learn. 2016; 1. PMid:30792896 https://doi.org/10.1038/npjscilearn.2016.11

[9] St. Lawrence College, Bachelor of Science in Nursing (BScN). [cited 2015 Oct 17]. Available from: https://www.stlawrencecolleg e.ca/programs-and-courses/full-time/programs/a_m/b achelor-of-science-in-nursing-bscn/kingston/

[10] Mills D, Alexander P. Small Group Teaching: A Toolkit for Learning. Higher Education. 2013; 36. Available from: https://www.heacademy.ac.uk/sites/default/files/re sources/Small_group_teaching_1.pdf

[11] Swain H. Peer-assisted learning (PAL) [Internet]. University of Glasgow. 2008; 1-87. Available from: http://www.timeshighereducation.co.uk/news/peer -assisted-learning-pal/210078. article

[12] Capstick S. Benefits and Shortcomings of Peer Assisted Learning (PAL) in Higher Education: an appraisal by students. In: Peer Assisted Learning Conference, Bournemouth. 2004; 1-53.

[13] White P, Rowland AB, Pesis-Katz I. Peer-Led Team Learning Model in a Graduate-Level Nursing Course. J Nurs Educ. 2012; 51(8): 471 5. PMid:22766075 https://doi.org/10.3928/01484834-201 20706-03

[14] Brannagan KB, Dellinger A, Thomas J, et al. Impact of peer teaching on nursing students: Perceptions of learning environment, selfefficacy, and knowledge. Nurse Educ Today. 2013; 33(11): 1440-7. PMid:23260616 https://doi.org/10.1016/j .nedt.2012.11 .018

[15] Christiansen A, Bell A. Peer learning partnerships: Exploring the experience of pre-registration nursing students. J Clin Nurs. 2010; 19(5-6): 803-10. PMid:20500324 https://doi.org/10.1111/j. 1365-2702.2009.02981. $\mathrm{x}$
[16] Stone R, Cooper S, Cant R. The value of peer learning in undergraduate nursing education: a systematic review. ISRN Nurs. 2013; 2013: 1-10. Available from: http://ovidsp. ovid.com/ovidweb.cgi? $\mathrm{T}=\mathrm{JS} \& P A G E=r$ ef erence $\mathrm{D}=\mathrm{prem} \& N E W S=\mathrm{N} \& A N=23691355 \% 5 \mathrm{Cn}$ PMid:23691355 https ://doi .org/10.1155/2013/930901

[17] Notarnicola I, Petrucci C, De MR, et al. Complex adaptive systems and their relevance for nursing: An evolutionary concept analysis. 2017. PMid:28177175 https://doi.org/10.1111/ijn.12522

[18] Mitchell GJ, Pilkington B, Jonas-Simpson CM, et al. Nursing education and complexity pedagogy: Faculty experiences with an elearning platform. J Nurs Educ Pract. 2016; 6(5). https://doi.or g/10.5430/jnep.v6n5p60

[19] Mitchell GJ, Jonas-Simpson CM, Cross N, et al. EXPERIENCE EXCHANGE Innovating nursing education: interrelating narrative, conceptual learning, reflection, and complexity science. J Nurs Educ Pract. 2013; 3(4). https : //doi .org/10.5430/jnep.v3n4p30

[20] St. Lawrence College. Annual Report 2016-2017 [Internet] SEAMEO RIHED Annual Report. 2017. Available from: https://mnre.gov.in/file-manager/annual-report/20 16-2017/EN/pdf/1.pdf\%OAwww.rihed. seameo.org

[21] Colleges Ontario. Student and Graduate Profiles 18. 2018.

[22] Colleges of Nurses of Ontario. Applicant Statistics Report 2016. Toronto, ON; 2017.

[23] Garwood JK, Ahmed AH, McComb SA. The Effect of Concept Maps on Undergraduate Nursing Students' Critical Thinking. Nurs Educ Perspect. 2018; (August): 1. Available from: http://www.ncbi.nlm.nih.gov/pubmed/29629932\%0Ahttp: //Insights . ovid. com/crossref $? a n=00024776-900000000$ $-99800$

[24] Lee W, Chiang CH, Liao IC, et al. The longitudinal effect of concept map teaching on critical thinking of nursing students. Nurse Educ Today. 2013; 33(10): 1219-23. PMid:22795871 https://doi.or $\mathrm{g} / 10.1016 / \mathrm{j}$. nedt .2012 .06 .010

[25] Mammen JR. Computer-Assisted Concept Mapping: Visual Aids for Knowledge Construction. J Nurs Educ. 2016; 55(7): 403-6. PMid:27351610 https://doi.org/10.3928/01484834-20160 615-09

[26] Woods DR. Preparing for PBL. Hamilton ON; 2006; 1-336.

[27] Morris D, Turnbull P. Using student nurses as teachers in inquirybased learning. J Adv Nurs. 2004; 45(2): 136-44. PMid:14705998 https://doi.org/10.1046/j.1365-2648.2003.02875.x

[28] Patterson C, Stephens M, Chiang V, et al. The significance of personal learning environments (PLEs) in nursing education: Extending current conceptualizations. Nurse Educ Today. 2017; 48: 99-105. PMid:27744138 https://doi.org/10.1016/j.nedt.2016.09 .010 